\title{
Correction to: Effect of Pre-hydrolysis on Simultaneous Saccharification and Fermentation of Native Rye Starch
}

\author{
Ewelina Strąk-Graczyk ${ }^{1}$ (D) - Maria Balcerek ${ }^{1}$ (D)
}

Published online: 23 May 2020

(C) Springer Science+Business Media, LLC, part of Springer Nature 2020

\section{Correction to: Food Bioprocess Technol} https://doi.org/10.1007/s11947-020-02434-9

The original version of this article unfortunately contained some mistakes as the last image (Figure 6) does not include statistics (letters) as described in caption.

With this, the correct figure is herewith published.
Publisher's Note Springer Nature remains neutral with regard to jurisdictional claims in published maps and institutional affiliations.

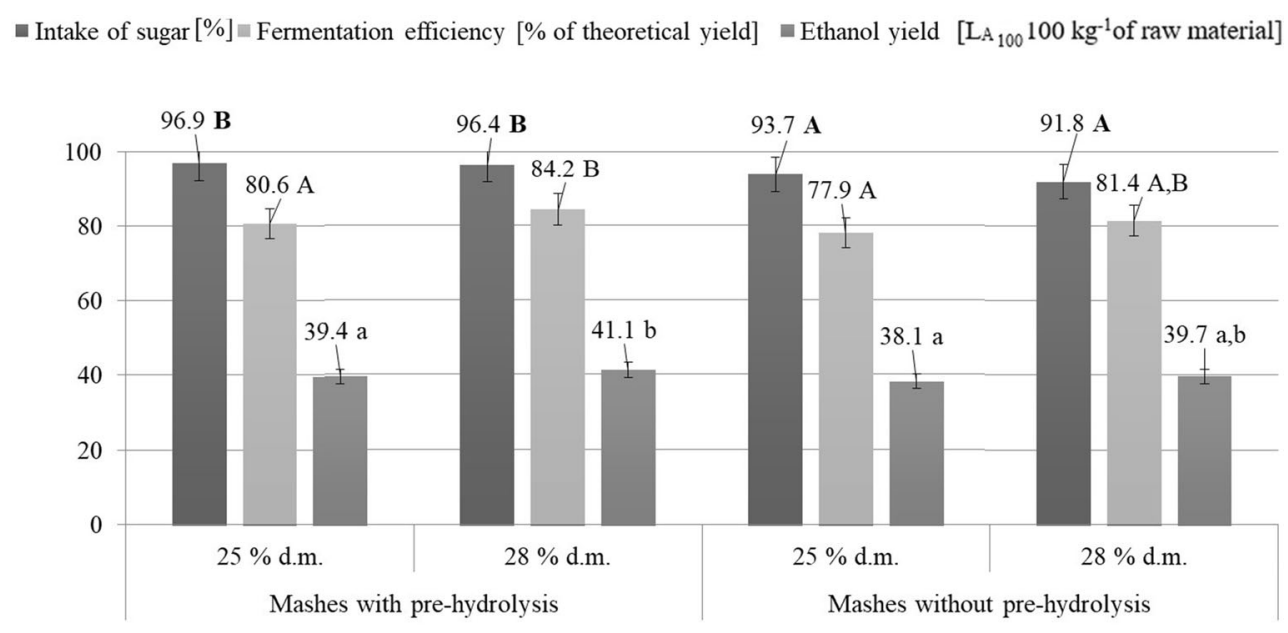

Variants

The original article has been corrected.

The online version of the original article can be found at https://doi.org/ 10.1007/s11947-020-02434-9

Ewelina Strąk-Graczyk

ewelina.strak-graczyk@dokt.p.lodz.pl

1 Institute of Fermentation Technology and Microbiology, Faculty of Biotechnology and Food Sciences, Lodz University of Technology, Wolczanska 171/173, 90-924 Lodz, Poland 